\title{
PRÁTICAS SUSTENTÁVEIS ORIENTADAS PELO DESIGN: RELATO DA PROJETAÇÃO DE UM EVENTO
}

\author{
Ana von F. Berger, MSC \\ Gabriela W. Zambenedetti; (UNIRITTER) \\ Carolina H. Eichenberg, MSC; (UNIRITTER )
}

PALAVRAS CHAVE

sustentabilidade; rede de projeto; design estratégico; design social.

KEYWORDS

sustainability, design networks, strategic design, social design.

\section{RESUMO}

Este artigo relata a experiência de concepção de um evento orientada pelo Design Estratégico e baseada nos princípios da sustentabilidade. Trata-se de um congresso voltado ao público escolar, cujo objetivo central consistia em levar o interesse pela pesquisa científica aos professores e estudantes de ensino fundamental tendo como pano de fundo a temática da sustentabilidade. A equipe de Design buscou um alinhamento com práticas de sustentabilidade nos âmbitos social, econômico e ambiental, o que determinou as estratégias projetuais adotadas, as ações e os materiais desenvolvidos para o evento. Como resultados práticos desta atuação viu-se a formação de uma rede de atores envolvidos com a prática da sustentabilidade, o que levou a qualificação de ambientes educativos e ao compartilhamento de habilidades e conhecimentos. O caso apresenta a abordagem do Design Estratégico enquanto articuladora de redes através do entendimento sistêmico de projeto, o qual foi direcionado para o engajamento de atores que estariam fora de um projeto tradicional de evento, reforçando o viés de sustentabilidade social. O Design Estratégico, neste caso, converge com a abordagem do Design Social na medida em que se destaca uma preocupação social, sobretudo na inclusão de grupos produtivos de baixa renda para a confecção de produtos para o evento.

\section{ABSTRACT}

This paper reports a Strategic Design driven event, based on principles of network and sustainability. This event was focused on students from public schools, and its main objective was to take an interest in scientific research on sustainability to teachers and elementary students. The design team sought alignment with sustainability practices in social, economic and environmental spheres, which determined the adopted design strategies, actions and materials developed for the event. As results, this actions saw the formation of a network engaged and involved with the practice of sustainability, which led to qualifying educational environments and the sharing of skills and knowledges. The case shows Strategic Design as a network articulator through a systemic understanding of the design practice, focusing on engaging actors not traditionally involved in the process, thus reinforcing the social sustainability dimension. Strategic Design, in this case, converges with the Social Design approach when it highlights social concerns, especially on including low income productive groups for the manufacture of products for the event.in the context of public policy. 


\section{INTRODUÇÃO}

Mudanças sociais e econômicas da última década evidenciam novos paradigmas, destacando-se o da sociedade do conhecimento e o da rede, através dos quais novos modelos de produção se desenvolvem. Segundo Castells (2005), essa nova morfologia social modifica a operação e os resultados dos processos produtivos e de experiências. Conexões em rede da sociedade contemporânea modificam o valor das dinâmicas sociais, tanto na economia como na cultura, no consumo e na localização geográfica. Nesse sentido, as estruturas em rede possibilitam conectar territórios com diferentes culturas, favorecendo o intercâmbio de informações e o alcance de novas soluções. Quanto mais vínculos são formados, maior é a troca de informação e mais autossustentável se torna o contexto local.

O design tem a possibilidade de atuar na complexidade da sociedade do conhecimento e dentro das redes que dela surgem principalmente pelo seu pensamento sistêmico, integrador e visual, encontrado em poucas áreas (CARDOSO, 2011). A condução de um projeto em rede busca se focar na visão de todos os atores envolvidos no processo. Este desafio deve ser enfrentado nas diferentes fases do desenvolvimento de uma solução, propondo metodologias integradoras de visões compartilhadas (KRUCKEN; MERONI; 2006).

Este artigo relata a experiência de concepção e execução de um evento baseada nos princípios da sustentabilidade e orientada pelo Design Estratégico. Trata-se de um congresso voltado ao público escolar, cujo objetivo central consistia em levar o interesse pela pesquisa científica aos professores e estudantes de ensino fundamental tendo como pano de fundo a temática da sustentabilidade. A equipe de design buscou um alinhamento com a lógica de rede, de forma a conectar atores de diferentes empreendimentos sociais na produção do evento; também considerou práticas fundamentadas nos três pilares da sustentabilidade: ambiental, econômica e social. Destacam-se as ações no âmbito da sustentabilidade social, em especial a inclusão de grupos produtivos de baixa renda e a gincana promovida com 29 escolas da rede municipal da cidade de Viamão, no Rio Grande do Sul.

O artigo está estruturado da seguinte forma: (a) breve introdução ao conceito de Design Estratégico; (b) relato do caso: o congresso, briefing e estratégias de projeto, descrição do evento e mapa de atores; (c) resultados e discussão e (d) considerações finais.

\section{DESIGN ESTRATÉGICO}

Compreendendo que a atividade de Design adquiriu um significado mais amplo e seus objetivos se expandiram para além da forma e função de um produto, diversas abordagens são propostas, sendo uma delas a do Design Estratégico, definido como uma abordagem projetual para resolver problemas complexos de forma interdisciplinar e sistêmica, ancorado em uma cultura de projeto.

O antigo paradigma de fazer Design deu lugar a ideia de um sistema, composto pela integração entre comunicação, serviço e experiências ligados a um produto tangível ou intangível. Este conceito denomina-se sistema-produto: um conjunto de atributos materiais e imateriais que atuam sobre um bem e a sua percepção por parte das pessoas. Na emergência dessa complexidade, o designer passa a trabalhar em conjunto com outros campos de conhecimento que enriquecem de forma fundamental os resultados dos projetos, tais como ciências sociais e psicologia. Cria-se, desse modo, uma cultura de projeto que é capaz de entender, visualizar, orientar e comunicar os conhecimentos adquiridos na forma de inovação e ressignificação dos bens de consumo (GALISAl; BORBA; GIORGI, 2008).

O Design Estratégico, portanto, é uma evolução do paradigma de design baseado no produto como um bem concreto para um sistema mais complexo que, por consequência, exige uma outra abordagem projetual capaz de articular o conhecimento de forma eficiente. Como compreende Ikeda (2007), esta competência estratégica pode se dar tanto dentro de empresas com o objetivo de alcançar vantagens competitivas e aumentar as margens de lucro, como também fora de uma estrutura corporativa em qualquer processo de Design que envolva uma abordagem de projeto ampla e reflexiva. Não se vincula só e necessariamente a objetivos econômicos, mas também possui habilidades úteis para trabalhar em projetos de natureza social.

Conceituando-se rede como um conjunto de nós interconectados (CASTELLS, 1999), ao considerar-se o conjunto de atores estabelecidos em projetos, tem-se que a atuação do designer envolve a articulação e mediação do conhecimento que circula por esses nós. Esta mediação está baseada na capacidade do designer de se tornar agente de diferentes organizações na sociedade e de propor significados, linguagens e até valores ligados a cidadania e participação social (VERGANTI, 2009).

Reforçando a atuação Victor Papanek (1973), precursor do chamado Design Social que desde o início dos anos 
1970 percebeu sustentabilidade como critério indispensável para o desenvolvimento de um bom projeto de Design, temos que "o design deve ser uma ferramenta inovadora, multidisciplinar e criativa para responder às necessidades humanas", o que confere aos designers a responsabilidade de projetar sistemas-produto-serviço com propósito. $\mathrm{Na}$ medida em que o Design se torna uma ferramenta significativa para as mudanças sociais e ambientais, cresce a responsabilidade moral e social de seus projetos, com um foco especial nas pessoas que são impactadas pelo processo de Design.

No caso deste projeto, pode-se traçar uma aproximação entre o Design Estratégico e o Design Social, definido por Lima e Martins (2011) como uma abordagem de projeto participativa envolvida na promoção de valores sustentáveis, sociais e culturais, pois há um esforço da equipe de design em integrar os eixos de design para o mercado e design com preocupações sociais, colocados em oposição por Margolin e Margolin (2004). Dessa maneira, para a produção da cenografia e dos brindes do evento, optou-se por valorizar grupos produtivos locais de baixa renda e materiais reaproveitados, ao invés de contratar empresas de outros estados que oferecem produtos prontos para eventos. A seguir, apresenta-se o relato da projetação do evento e os resultados observados

\section{O CONGRESSO}

Em abril de 2014 aconteceu na cidade de Viamão (RS) o I Congresso de Agroenergia e Sustentabilidade na Educação. Esse evento fez parte de um programa de ações que constituem o $\mathrm{PROMOBIO}$, um projeto científico-tecnológico dos órgãos Finep e CNPq, alocado em uma Instituição de Ensino Superior do Rio Grande do Sul. O programa promove ensino, pesquisa e extensão na área de biocombustíveis, especificamente biodiesel e etanol. O PROMOBIO tem como missão proporcionar a integração entre escolas, universidade e empresas.

Para promover tal integração, foram realizadas ações com 15 escolas de ensino básico e fundamental dos municipios de Porto Alegre e Viamão com intenção de despertar nos alunos vocações para carreiras nos setores de biocombustíveis, petróleo, gás e petroquímica — setores em que há carência de recursos humanos qualificados. O I Congresso de Agroenergia e Sustentabilidade na Educação marcou o encerramento de tal ciclo de atividades nas escolas, quando durante três dias a comunidade local foi convidada a conhecer os resultados do PROMOBIO e teve a oportunidade de participar de atividades coletivas, cursos de formação continuada, conhecer projetos de pesquisa escolar, acadêmica e empresarial, além de ter contato com uma rede de profissionais e pesquisadores da área de bioenergia e trocar experiências com colegas.

\subsection{Briefing e estratégias de projeto}

Para organizar e promover o I Congresso de Agroenergia e Sustentabilidade na Educação foi contratada uma equipe atuante em Design Estratégico. O desafio inicial proposto à equipe constituiu-se em promover o tema do Congresso junto ao público alvo do evento (alunos e professores do ensino fundamental), bem como materializar os conceitos de agroenergia e sustentabilidade nas propostas de ambientação/cenografia, nos souvenirs e memorabílias do evento, e nos materiais impressos para divulgação.

Como visto, a abordagem estratégica do Design baseia-se na interdisciplinaridade e na visão sistêmica em projetos, resultando em soluções materiais e imateriais na forma de sistemas-produto-serviço que preconizam a criação de redes de atores diversos e que propõem novas significações que contemplam questões de cunho social. A partir desta perspectiva, iniciou-se um processo de exploração dos conceitos associados ao I Congresso de Agroenergia e Sustentabilidade.

Esta exploração foi realizada por meio de um brainstorming não estruturado. Esta atividade permitiu o compartilhamento do conhecimento prévio da equipe acerca dos temas-chave do evento e permitiu a associação de novos significados aos conceitos propostos previamente pelo comitê organizador do Congresso. Além da associação de novos significados, foi possível definir com objetividade os protagonistas do Congresso que se realizaria: os alunos das escolas e seus professores, responsáveis por sua participação no evento.

A partir da exploração da palavra "educação", passou-se a abordar o evento como uma experiência de aprendizagem a ser proposta a alunos, professores, profissionais e pesquisadores que transitariam no evento. Entendeu-se que o Congresso não deveria ser apenas o fechamento de um ciclo de ações educativas previamente realizadas, mas um marco que levaria novas propostas de como os atores presentes poderiam se valer dos conhecimentos do PROMOBIO em seu dia a dia.

A partir da exploração da palavra "sustentabilidade", por sua vez, a equipe percebeu a abrangência e a importância de tal conceito. No entendimento de Manzini 
(2008), a sustentabilidade requer uma descontinuidade do sistema fragmentado atual, substituída pela construção de um sistema aberto e interconectado na sua complexidade que possibilita uma diversidade de alternativas sustentáveis e plausíveis. Formas emergentes de capitalismo, estratégias de implementação de práticas sustentáveis, construção de cenários futuros e estabelecimento de parcerias e cooperação levando em conta a justiça social e a inclusão são temas discutidos em torno de uma proposta mais abrangente de ações sustentáveis (ELKINGTON, 2011). Considerando a amplitude e a complexidade do conceito, a equipe determinou como norteador das ações do projeto o tripé da sustentabilidade de John Elkington (2011), um conceito ampliado de sustentabilidade principalmente direcionado às empresas que visam práticas sustentáveis e composto por três pilares: social, econômico e ambiental.

Por fim, a partir da exploração da palavra "agroenergia" a equipe de design verificou o distanciamento do conceito com o cotidiano do público-alvo, composto em maioria por alunos e professores de escolas municipais. O Brasil é referência na produção de agroenergia, que é a segunda maior fonte de energia primária do país, segundo o portal do Ministério da Agricultura (2015). Possui programas que atraem a atenção do mundo por ofertar alternativas econômica e ecologicamente viáveis à substituição dos combustíveis fósseis, cujo uso já é conhecido e corriqueiro no nosso dia a dia.

Feita a exploração e o entendimento dos conceitos, foram definidas como estratégias de projeto a adoção da perspectiva de formação de rede e a exploração dos pilares da sustentabilidade. Assim, definiu-se que todas as ações relativas ao Congresso seriam articuladas no intuito promover novas formas de relacionamento entre as pessoas e o engajamento destas com as dimensões da sustentabliidade. Entre as estratégias de projeto adotadas, destacam-se:

- A criação de um canal de comunicação do Congresso em uma rede social amplamente utilizada pelo público em questão, possibilitando o contato direto e prévio ao evento com cada um dos participantes que estariam presentes;

- A participação dos alunos e professores em atividades lúdicas e pedagógicas anteriores ao Congresso, através das quais se estimulariam o engajamento, a competição e a cooperação entre as instituições de ensino;

- A articulação de uma ou mais dimensões da sustentabilidade propostas no tripé da sustentabilidade em cada material desenvolvido e ação realizada para o Congresso, considerando meios de produção, consumo e descarte;

- A inclusão de grupos produtivos de comunidades de baixa renda de Porto Alegre na confecção de materiais de divulgação, decoração e brindes do Congresso.

\subsection{A Gincana Sustentável}

Considerando o conceito do tripé da sustentabilidade e a premissa de que os vínculos precisariam ser fortalecidos em uma relação em rede com o público do congresso, entendeu-se a necessidade prévia de engajar e disseminar junto ao público temáticas relacionadas a sustentabilidade e agroenergia. Para tanto, a equipe de Design desenvolveu uma gincana como forma de promover a participação direta e indireta no Congresso que foi realizada junto a 29 escolas da rede municipal da cidade de Viamão (RS). Esta gincana teve o nome de Gincana Sustentável.

Pensada como ação educativa e de engajamento inicial, a Gincana Sustentável propôs atividades que levaram em conta o universo da sustentabilidade e variaram desde coleta de óleo de cozinha usado, até criação de horta comunitária e fanzine temática nas escolas participantes.

Para auxiliar a participação e o engajamento das escolas na gincana, foi desenvolvido um material de instrução para realização de tarefas, com pontuação relativa a cada uma delas. As escolas receberam esse material, composto por um "kit" de cartas das atividades para participar da Gincana Sustentável e por um cartaz de divulgação do I Congresso de Agroenergia e Sustentabilidade na Educação. Essa distribuição foi feita para os representantes das escolas e se deu em um evento de lançamento da atividade, promovido pela Prefeitura do município de Viamão (RS).

O "kit" da Gincana Sustentável foi projetado para ser desmembrado, permitindo que o representante de cada escola organizasse grupos de articulação para cada atividade da gincana. Após a sua conclusão, as escolas deveriam postar fotos de registro na fanpage do Congresso, previamente publicada em uma popular rede social, o Facebook, inserindo na legenda 
uma "hashtag" seguida do nome da escola e da atividade realizada.

Essa ação nas redes sociais gerou a participação intensa das escolas do município de Viamão. A Gincana Sustentável movimentou a campanha de engajamento através da rede social, e além das atividades da Gincana Sustentável foram trabalhadas inscrições no evento e disponibilizados conteúdos relacionados ao tema do Congresso. Tal ação teve como resultado o alcance de mais de 2.300 pessoas no Brasil, Estados Unidos e Portugal.

\subsection{Cenografia e decoração}

Como exemplo de organização em rede, a maior parte da decoração que compôs a cenografia do evento foi concebida junto com e produzida por grupos produtivos de artesanato locais em situação de vulnerabilidade social. A cenografia foi toda feita de material reutilizado, como garrafas PET e sacos de pão torcidos. A decoração conquistou os participantes do I Congresso de Agroenergia e Sustentabilidade que, ao final do evento, solicitaram o reuso como decoração das escolas do municipio.

O grupo produtivo envolvido com a produção da cenografia foi co-responsável pelos materiais necessários para tanto. O grupo mobilizou a comunidade de seu bairro na coleta das centenas de garrafas PET que viraram os elementos de cenografia e decoração do evento. Para a intervenção artística nas garrafas PET foi estabelecido o uso de materiais não nocivos ao meio ambiente, como tintas a base de água. Para a composição dos módulos da decoração, foi utilizado uma tecnologia social adaptada pelo grupo: o "ecofio". O ecofio consiste em fios feitos de pedaços de sacos de pão torcidos, os quais foram utilizados para unir as partes das garrafas, fazendo as vezes de barbantes e fios sintéticos comumente utilizados.

No decorrer do Congresso, afirmando o estabelecimento de uma rede de atores relacionados ao projeto do evento, o grupo em questão teve também a oportunidade de ministrar oficinas junto a alunos, professores e pesquisadores, compartilhando seu conhecimento prático relacionado a reciclagem e reuso de materiais descartados.

\subsection{Souvenirs e memorabílias}

Os souvenirs e memorabílias foram propostos a fim de oferecer aos participantes do Congresso lembranças de sua participação no evento. Estes materiais foram elaborados pela equipe de Design e produzidos em parceria com grupos de artesãos dos municípios de Viamão e Porto Alegre. Para o estabelecimento de uma cadeia virtuosa de produção, parte dos insumos coletados na gincana sustentável serviu de matéria-prima para a produção de souvenirs.

O óleo de cozinha coletado pelos estudantes na gincana, por exemplo, foi utilizado para a produção de sabão por um dos grupos produtivos envolvidos. O sabão gerado pela transformação do óleo fez parte dos souvenirs entregues aos participantes inscritos. Para o armazenamento deste sabão foi produzida uma embalagem de garrafa PET, executada pelo mesmo grupo responsável pela cenografia do evento.

Todos os souvenirs e memorabílias recebidos pelos participantes do evento foram entregues em uma sacola produzida por um terceiro empreendimento. Esta sacola foi feita com pedaços de cortinas reaproveitados e suas alças feitas de restos de persianas, cintos e alças de mochilas dos correios em desuso.

Ainda, os crachás de identificação dos participantes do evento foram criados pensando em mais uma ação de engajamento junto as escolas participantes do evento. Produzido por outro grupo produtivo, o papel utilizado era um "papel-semente", que permitiu que os crachás pudessem ser plantados nas escolas após a participação de seus alunos no Congresso.

Figura 1 - Materiais produzidos para

o I Congresso de Agroenergia e Sustentabilidade.

Fonte: elaborado pelos autores, com base na pesquisa realizada.
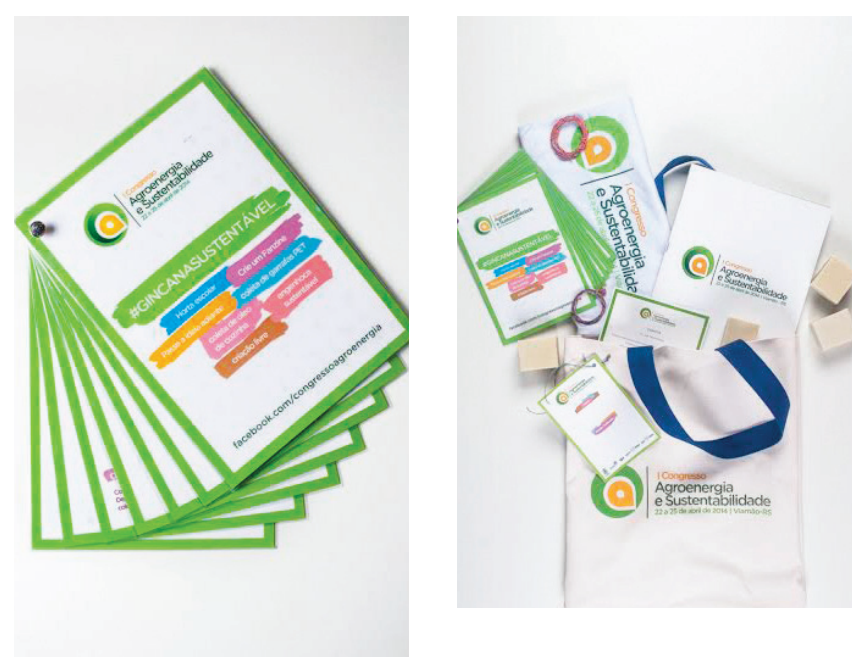

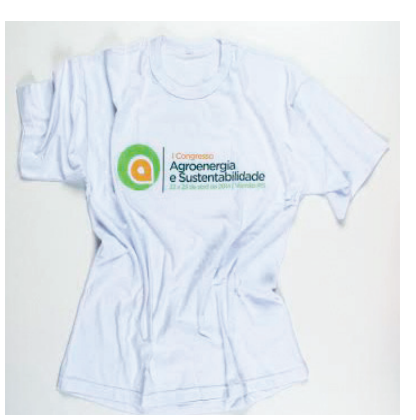




\subsection{Mapa da rede e das ações promovidas}

O trabalho da equipe de Design propôs a criação intencional de uma rede de colaboradores e participantes, que direta ou indiretamente trocaram conhecimentos e habilidades. A seguir, é apresentado o mapa de atores envolvidos ao longo do projeto do Congresso.
- O engajamento de diretores de escola, professores e alunos em atividades que propuseram a melhoria do ambiente escolar, e a união destes em torno de um propósito benéfico ao meio ambiente e à sociedade em geral;

- Atividades como "coleta de garrafas PET", "coleta de óleo de cozinha" resultaram na mobilização da comunidade do

Figura 2 - Mapa de atores envolvidos no I Congresso de Agroenergia e Sustentabilidade.

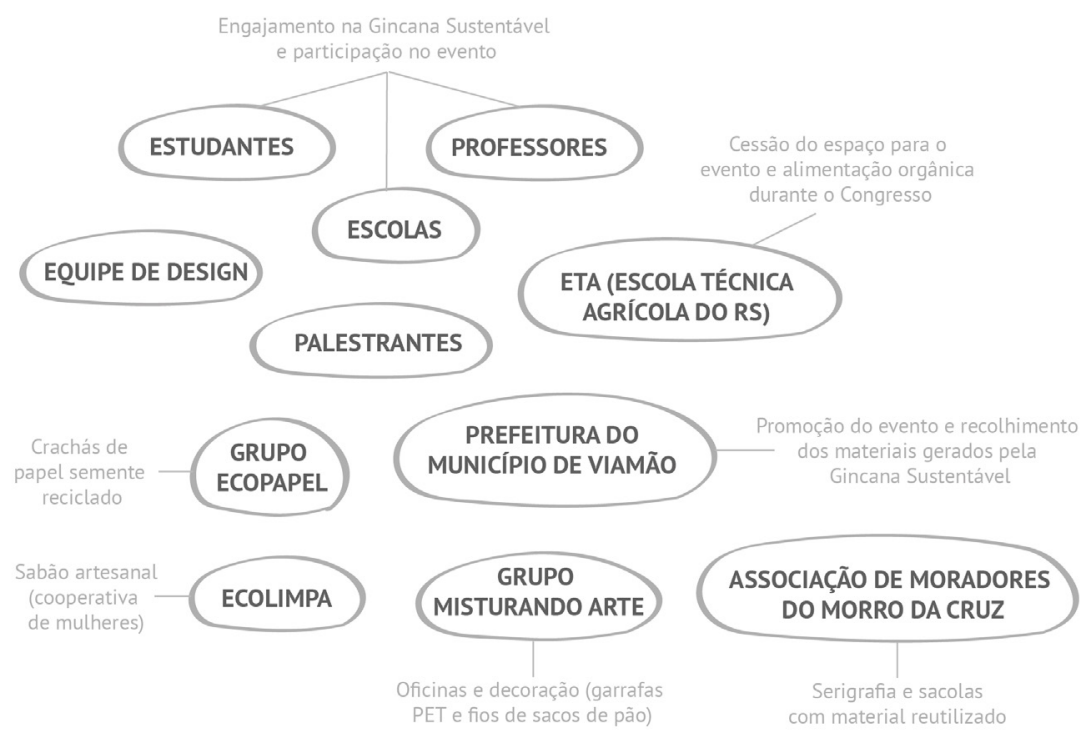

Fonte: elaborado pelos autores, com base na pesquisa realizada.

\section{RESULTADOS E DISCUSSÃO}

As necessidades do evento em questão foram atendidas através da promoção da sustentabilidade plena. Entende-se no arranjo formado entre empresas de design e grupos produtivos de baixa renda uma oportunidade de atuação que propõe benefícios diretos e indiretos para a sociedade através do contato entre pessoas, da troca entre disciplinas, do uso de insumos reaproveitados e da ação educativa resultante.

A participação das escolas foi intensa: antes, durante e após a realização do evento. Acredita-se que a Gincana Sustentável foi uma ação diferenciada no que tange à mobilização e ao engajamento do público-alvo e suas instituições, e teve como efeito não esperado a extensão das ações para além dos muros das escolas. Ao todo, foram coletados 2.267 litros de óleo de cozinha usado e 111.285 unidades de garrafas PET.

Avalia-se que as ações promovidas pela equipe de Design tiveram como principais resultados: entorno das escolas na arrecadação de materiais e insumos para a realização de atividades da Gincana Sustentável.

- O compartilhamento de conhecimento e conteúdos gerados pelos alunos para fora dos muros das escolas, com atividades como "passe adiante" (produção de um material informativo sobre sustentabilidade para distribuir na comunidade) e a criação de "fanzines", estendendo a ação educativa para atores indiretamente envolvidos com a escola;

- Sugeriu aos professores meios de abordar a sustentabilidade de forma interdisciplinar, desafiandoos a serem mais criativos em suas aulas ao passo que promoveu nos alunos a iniciativa e a proatividade;

- O incentivo à intervenção obteve como resultados a qualificação do espaço físico escolar com a realização de atividades como "horta na escola" e "criação livre"; 
- Troca de conhecimento acadêmico e popular, com destaque para a aproximação de grupos produtivos de baixa renda com o Congresso através de oficinas de reutilização criativa de materiais.

\section{CONSIDERAÇÕES FINAIS}

Novas maneiras de se relacionar, de perceber a realidade e de resolver os problemas cotidianos são solicitadas para a transição sustentável. Essas mudanças se apoiam no entendimento de novos valores sociais que dependem, por sua vez, da interação dos indivíduos e de suas habilidades, os quais passam a ser a engrenagem principal de um sistema com propósito maior. Esse sistema pode se desenvolver na lógica de interações e interdependência das partes de um todo, como ocorre na formação de redes, e assim constituir uma economia baseada no conhecimento, que contribui não apenas com benefícios econômicos e produtivos, mas também ambientais e sociais.

Na dinâmica de projetação do I Congresso de Agroenergia e Sustentabilidade na Educação nota-se a prática sustentável não somente pelo seu caráter de reuso e reciclagem de materiais, na dimensão ambiental, mas também pela oportunidade de participação e geração de renda que tiveram os grupos produtivos envolvidos, e em vivências possibilitadas pela Gincana, que promoveram a atitude responsável e a interação entre estudantes, professores e comunidade. Desta forma, aliada a formação de uma rede de atores oriundos de diversos contextos, nota-se a inclusão dos três pilares da sustentabilidade na concepção do evento.

Destacam-se as ações feitas dentro do pilar de sustentabilidade social, por terem promovido o engajamento de atores que estão fora do sistema de produção que apoia o mercado de eventos. Por exemplo, as sacolas ecológicas feitas com pedaços de cortina reaproveitados por um dos empreendimentos envolvidos na confecção normalmente seriam produzidas em um sistema de larga escala, o que tornaria seu preço mais competitivo, porém explorando mão de obra barata. Outra ação que articulou os participantes do evento em rede e aproveitou para promover ações sobre o tema sustentabilidade foi a Gincana Sustentável. Os alunos e professores das 29 escolas da rede municipal da cidade de Viamão tiveram a oportunidade de entender e experimentar de forma colaborativa tópicos que mais tarde foram consolidados no evento.

O Design Estratégico se mostrou uma disciplina capaz de articular uma rede diversificada em um contexto de projeto com foco na sustentabilidade, valendo-se do en- tendimento sistêmico do tema. A equipe de Design, diante do desafio recebido, mostrou um posicionamento que compreende um sistema de escolhas conscientes. Ao invés de apenas criar soluções que responderiam as requisições do comitê organizador do Congresso, a equipe propôs alternativas executadas por sujeitos inicialmente alheios ao projeto, mas que, impactados pelo processo de projetação, trabalharam alinhados às estratégias propostas.

O Design Social cria produtos e serviços com o objetivo de provocar melhorias sociais. O Design Estratégico, neste caso, converge com a abordagem do Design Social na medida em que ultrapassa a perspectiva de somente projetar e vender produtos para o mercado para uma perspectiva de incluir o eixo social na prática de projeto.

\section{REFERÊNCIAS}

CARDOSO, R. Design para um mundo complexo. São Paulo: Cosac Naify, 2011.

CASTELLS, M. A Sociedade em Rede. Paze Terra, São Paulo, 2005.

ELKINGTON, J. Sustentabilidade: canibais com garfo e faca. São Paulo: Makron, 2011.

GALISAI, R.; BORBA, G. S.; GIORGI, R. F. Design como cultura de projeto e como integração entre universidade e empresa. 8 Congresso de Pesquisa e Desenvolvimento em Design. Porto Alegre, 2008.

KRUCKEN, L.; MERONI, A. Building Stakeholder Networks To Develop And Deliver Productservice-Systems: practical experiences on elaborating pro-active materials for communication. Journal of Cleaner Production, 2006, in press by Elselvier.

MANZINI, E. Design para Inovação Social e Sustentabilidade: Comunidades Criativas, organizações colaborativas e novas redes projetuais. E-papers: Rio de Janeiro, 2008.

MINISTÉRIO da Agricultura. Desenvolvimento sustentável: agroenergia. Disponível em: <http://www.agricultura.gov. br/desenvolvimento-sustentavel/agroenergia>. Acesso em 20 de jun. 2015.

MARGOLIN, V; MARGOLIN, S. Um "modelo social" de design: questões de prática e pesquisa. Revista Design em Foco. Salvador, 2004. julho-dezembro,vol.I, número 001. pp 43-48. 